\title{
Investing in Capabilities and Reputation Pays Off for VC Firms
}

\author{
David Hsu (University of Pennsylvania)
}

KEYWORDS: Entrepreneurship, Venture Capital, Strategy, Startups.

New venture capital firms must make a variety of strategic decisions about market positioning and relationships with the entrepreneurs in their portfolio. One choice VC firms must make is whether to merely provide capital, or offer additional services-sometimes at a cost-to their portfolio companies.

A classic study that we published in August 2004 finds that many startups are willing to accept lower valuation terms for the reputation, resources and cachet of a top VC. This suggests that founders of new VC firms are likely to benefit from investing in a reputation of providing value-added services for entrepreneurs.

After studying 51 early-stage high-tech startups who were fielding a total of 148 competitive offers from VCs, we determined that the startups were three times more likely to accept financing offers from the VCs with the best reputations, and at the same time were willing to accept a $10-14 \%$ discount from valuation. These VCs can offer a new, unproven firm -- where the assets are the ideas and other intangibles that elude a dollar value -- something beyond an infusion of cash. The extra benefits include access to the VC's network, business referrals, experienced staff, management advice and cachet that helps them attract subsequent waves of financing from other VCs.

"These results are consistent with the idea that VCs act as more than strict financial intermediaries, placing funds from investors to capital-constrained start-ups," we wrote, adding. "This implies that the VC information network and its certification value may be more distinctive than their financial capital, and so these extrafinancial VC functions can have financial consequences, namely, the price at which VCs are able to acquire equity in a given start-up." We cite research that shows that top VCs invest their own money to build reputation, which in turn becomes a marketable asset that can be leveraged in negotiating with start-ups.
As an example of these "extra-financial" benefits, the Silicon Valley VC firm Kleiner Perkins Caufield \& Byers gives its portfolio companies some access to a body of information gleaned from other clients and has brokered more than 100 strategic alliances among them.

While it's cut and dried to compare only the dollar amounts of financing offers from different VCs, our research showed that entrepreneurs also value intangibles such as reputation. Experienced VC firms and their staffs can build value in the startup and drive its business in the right direction.

Note that we didn't study if trading dollar amounts for the VC's reputation affects the startup's performance, future valuation and outcome: whether it reached the IPO stage more quickly or got the products to market any faster.

"Nevertheless, the findings in this study are consistent with the theory that entrepreneurs who are tied into more connected networks at reputable VC firms expect to come across more opportunities for start-up growth, but must pay a premium for such access," our study concludes.

Our conclusions have withstood the 13 years time since this paper was published, and can offer some perspective for today's startups looking for financing.

\section{Editor's Comment}

Hsu's important study foreshadowed the high-touch service approach taken by many business accelerators and investors in recent years. While many VCs see this as a way of improving deal-flow, this research shows that building a reputation for being a great $\mathrm{VC}$ to work with fosters other benefits, including better terms for investors.

Many entrepreneurs see the primary benefit of 
accelerators as being access to capital. Data from the seed accelerator rankings project indicate that some accelerators are clearly better at providing access to capital than others. However, anecdotal evidence suggests that there is great variance among accelerators - even the top accelerators -in the costly investments made in training and developing entrepreneurs. Further research is warranted to identify the different costs and benefits for entrepreneurs of the different strategic currently being used by the venture investment community, including accelerators.

Jon Eckhardt

jeckhardt@wisc.edu(mailto:jeckhardt@wisc.edu)

\section{References}

David H. Hsu, "What Do Entrepreneurs Pay for Venture Capital Affiliation? (http://onlinelibrary.wiley.com/doi/10.1111/j.1540-6261. 2004.00680.x/abstract) ," The Journal of Finance, August 2004. 